\title{
HYPERPARATHYROIDISM HEALING IN PATIENTS TREATED FOR HYPERALDOSTERONISM: 3 CASES
}

Authors: Lourdes García Blasco, Juan Carlos Ferrer García, Mercedes Tolosa Torrrens, Pablo Sanz Revert, Crisitan Marco Alacid, Amparo Bartual Rodrigo, Carlos Sánchez Juan.

Hospital General Universitario de Valencia

Hyperaldosteronism usually presents with hypertension and hypokalemia; however, there is recent evidence of a relationship with the parathyroid hormone. There are different theories to try to clarify this relationship. Hyperaldosteronism treatment is medical or surgical depending upon etiology. We present three cases in which treatment solely for hyperaldosteronism also cured hyperparathyroidism

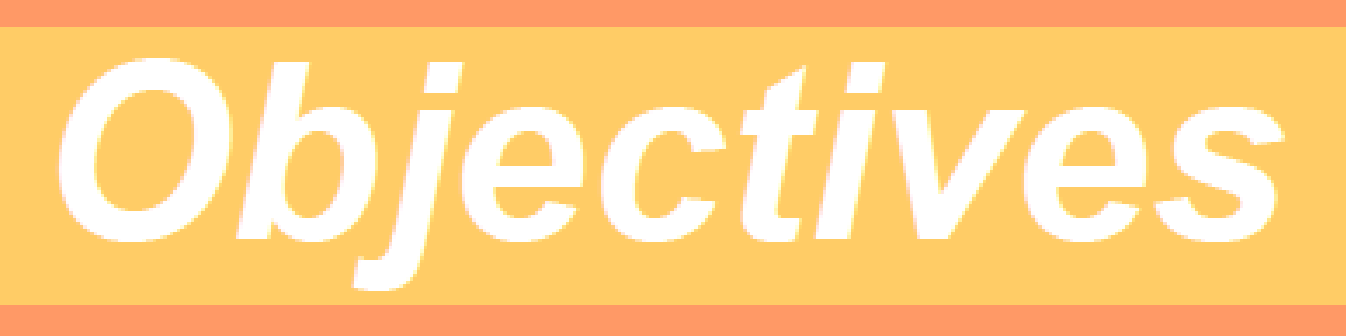

The aim of this study was to evaluate the impact of aldosterone excess on mineral metabolism.

We report three patients in whom hyperaldosteronism was diagnosed during 2015 and detected simultaneously hyperparathyroidism. We recorded epidemiological data, pre- and post-surgical phospho-calcium metabolism, as well as hyperaldosteronism.

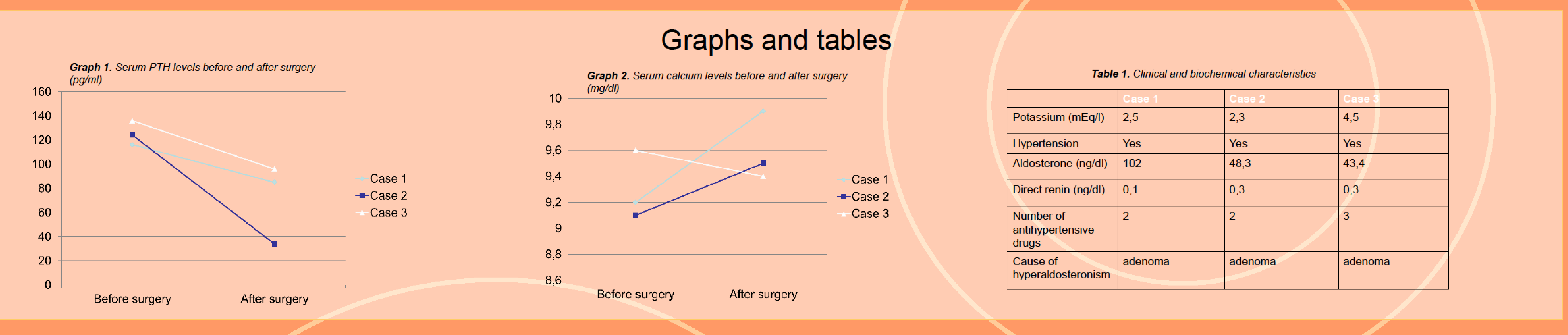

CASE 1: A 38 year old male was referred for suspected hyperaldosteronism. A nodule was detected in left adrenal in TC image. Levels of PTH $150 \mathrm{pg} / \mathrm{mL}$ were objectified with normal serum and urinary calcium and phosphorus. Levels of vitamin D were $19.9 \mathrm{ng} / \mathrm{mL}$. After left adrenalectomy, PTH levels were normalized.

CASE 2: A 55 years old woman referred for study of hypokalemia. Her PTH levels were $162 \mathrm{pg} / \mathrm{mL}$ with normal serum phosphorus and urinary calcium. Lesion $20 \mathrm{~mm}$ in left adrenal was detected in TC image. After adrenalectomy, PTH levels down to $34 \mathrm{pg} / \mathrm{mL}$.

CASE 3: A 63 years old woman was referred to rule out hyperaldosteronism. She presented PTH levels of $136 \mathrm{pg} / \mathrm{mL}$ and normal levels of serum calcium and phosphorus. Vitamin D levels were $24 \mathrm{ng} / \mathrm{ml}$. MRI image showed right adrenal injury that was removed. After surgery, PTH levels diminished.

In cases of primary hyperaldosteronism is advisable to assess the phospho-calcium metabolism, especially PTH. The effect on bone hyperaldosteronism long term is still unknown. In any case the calcium / phosphorus levels were pathological. Sometimes treatment solely of hyperaldosteronism can simultaneously treat hyperparathyroidism.

\begin{tabular}{|c|c|}
\hline References: & $\begin{array}{l}\text { Sariakjali B, Jamaspishvili E, Evran M, Sert M, Tetiker T. Primary hyperparathyroidism in a patient with primary aldosteronism. BMC Res Notes (2015) 8:310. } \\
\text { Vaidya A, Brown JM and Williams JS. The renin-angiotensin-aldosterone system and calcium-regulatory hormones. JHH (2015) } 29,515-521 \\
\text { Brown JM and Vaidya A. Interactions between adrenal-regulatory and calcium-regulatory hormones in human health. Curr Opin Endocrinol Diabetes Obes. (2014) } \\
\text { 21(3): 193-201. }\end{array}$ \\
\hline
\end{tabular}

